\title{
Influence of the Visitor Walking on Airflow and the Bioaerosol Particles in Typical Open Tomb Chambers: An Experimental and Case Study
}

\author{
Zhijian Liu *(D), Minnan Wu, Hongwei Cao, Yongxin Wang, Rui Rong and Hangyao Zhu \\ Department of Power Engineering, North China Electric Power University, Baoding 071003, China; \\ Minnanwu2020@163.com (M.W.); a8198061188@163.com (H.C.); YXwang@ncepu.edu.cn (Y.W.); \\ ncepu_rongrui@163.com (R.R.); ssszhy@126.com (H.Z.) \\ * Correspondence: zhijianliu@ncepu.edu.cn
}

check for updates

Citation: Liu, Z.; Wu, M.; Cao, H.; Wang, Y.; Rong, R.; Zhu, H. Influence of the Visitor Walking on Airflow and the Bioaerosol Particles in Typical Open Tomb Chambers: An Experimental and Case Study. Buildings 2021, 11, 538. https:// doi.org/10.3390/buildings11110538

Academic Editors: Paula Lopez-Arce and Ainara Zornoza-Indart

Received: 11 October 2021

Accepted: 12 November 2021

Published: 14 November 2021

Publisher's Note: MDPI stays neutral with regard to jurisdictional claims in published maps and institutional affiliations.

Copyright: (c) 2021 by the authors. Licensee MDPI, Basel, Switzerland. This article is an open access article distributed under the terms and conditions of the Creative Commons Attribution (CC BY) license (https:/ / creativecommons.org/licenses/by/ $4.0 /)$.
Abstract: Effective maintenance of ancient buildings is paid more and more attention worldwide. Many ancient buildings with high inheritance value were gradually destroyed, especially for murals in the open tombs. The bioaerosol particles (BPs) are the major source of contamination in murals and visitor walking could increase this hazard. In order to study the impact of visitors walking on the air flow and the distribution of BPs in the typical tomb chambers, the $k-\varepsilon$ and Lagrangian discrete phase model were adopted. The walking visitor was described by the dynamic mesh, and the concentration of BPs in the simulation was verified by experimental sampling. The distribution and migration mechanism of contamination in the chamber were dynamically analyzed. The results indicate that the denser vortex generated when a visitor was walking, and the concentration of BPs changed obviously. Therefore, the number of BPs deposited on some precious murals increased and the contamination location shifted in the direction of visitor walking. In addition, the deposition time of BPs was lagging which would cause potential risk. This research can provide scientific basis for reducing murals contamination during visitor visiting and a reference for the maintenance of ancient buildings.

Keywords: ancient buildings; bioaerosol particles; visitor walking; airflow disturbance; mural conservation

\section{Introduction}

As a vivid art form, mural display the painting style and characteristics of various historical periods, and has profound historical and cultural value. For an instance, a large number of Buddhist art murals have been preserved inside the Dunhuang Mogao Grottoes, a world cultural heritage site [1]. The open cultural sites can allow visitors to learn about history up close, increase cultural confidence, and local tourism revenue [2]. However, the air contains a lot of bioaerosol particles (BPs) (including fungi, bacteria, archaea, viruses, sensitized pollens, mold spores, and parasitic eggs etc.,), which would pose a serious threat to the murals [3]. The research of Sterflinger et al. [4] showed that rare cultural relics such as murals and stone carvings in chambers were difficult to be repaired once destroyed by BPs. In recent years, the influence of BPs on open tomb chambers cultural sites has become a hot issue in the field of cultural relic protection.

There is little doubt that due to the contact with the outside world, the indoor air pollution of these open chambers was quite serious [5]. Therefore, a large number of BPs outside are deposited on the surface of the murals by accumulation perennially. These BPs and the organic matter on the murals combine to produce pigments and form a biofilm on the mural surface, which affects the aesthetics of the mural and causes further structural damage [6-8]. Certain BPs could perform biological drilling on rock surfaces to form microchannels that strengthen their colonization on the mural. Moreover, the biofilms would be rapidly expanded under suitable environmental conditions of high relative 
humidity and low airflow velocity. [9]. The murals became loose and this environment would also affect the deposition of BPs on the surface of the mural [10]. The secretion of some BPs enabled unrecoverable modification of the mural painting layer color. Perhaps this is why there are brown, black, and other color spots that affect the beauty of the murals, such as the famous chamber murals of King Tutankhamun, the murals of Takamatsuka and Kitora Tumuli in Japan, etc. Several researchers investigated the growth law of fungi through a large number of experiments [11-13]. The results showed that the secretions of some fungi are very corrosive, and cause severe biodegradation of the murals when exposed to the environment. The mechanism of contamination from the internal causes of microbiology were revealed by extensive research $[9,14,15]$. The attachment of BPs to the wall would contribute to the biomineralization of the matrix. Therefore, a serious threat to the preservation of murals would be posed. Moreover, most of the research on the environmental microorganisms in burial chambers adopted the method of sampling and incubation, or used the analysis methods such as high-throughput sequencing and metagenomics to identify the microorganisms $[16,17]$. However, a greater threat to the protection of cultural treasures was posed by the continuous development of tourism in modern society.

Visitor's sightseeing also posed a serious threat to the chamber which is protected as open tourism cultural sites. W. Wang et al. [17] demonstrated seasonal dynamics of airborne fungi, and indicated that visitor visits have a non-negligible influence on the fungal concentration and colony composition in the chamber environment. The prehistoric Lascaux cave in France opened to visitors in 1948, but was forced to close in 1963 . The reason was that visitors' sightseeing had changed the original environment of the cave, leading to microbes outbreak of different types and affecting the color and structure of the murals [18]. Similarly, after nearly 30 years of tourism opening to the chamber of Tutankhamun in Egypt, the preservation environment of the chamber murals is getting worse and worse [11]. The increasingly serious problem of microbial contamination has eventually led to closures for visitors. Many precious caves have been completely closed in the hope of restoring their original ecological environment [12]. GCI (the Getty Conservation Institute) has done a large number of research since 1986 [19]. The damage to the cultural heritage of the cemetery is related to the behavioral activities of tourists. Demas. et al. used statistical methods to monitor the quantity, type, and visiting hours of tourists in the valley of the queens. As a result, a series of methods have been proposed, such as establishing an air filter at the inlet of the tomb, preventing bats and decayed animals from entering via the air vents, setting a glass barrier, etc., [20]. However, there is a lack of research on the diffusion mechanism of contaminants in the tomb chambers during the visitor walking. At the same time, few effective ways were put forward to protect these relics to open to visitors.

Visitors walking around in the tomb chamber is a dynamic process [21]. The distribution of BPs in the indoor air would be disturbed due to the wake generated by visitor' movement [22-24]. Numerical studies showed that there are obvious wake regions and unsteady vortex shedding on moving objects [25-27]. The BPs in the environment were carried to migrate by visitor walking. Tao et al. [28] used the dynamic mesh to simulate human walking. The results showed that a pair of counter-rotating vortices were formed behind the person, and then gradually extended to the space on both sides. This disturbance lasted for a period of time after the visitor stopped. In addition, J. Wang et al. [29] observed that the number of suspended particles in the indoor air would be reduced due to the movement of people. The study of Y. Wu et al. [30] also showed that the human body changes the airflow in the room while walking, and the shift of BPs is strengthened in the horizontal and vertical directions. Most of the research on air distribution caused by human movement were to reveal the spatial migration mechanism of BPs in closed medical rooms under mechanical ventilation. Therefore, the probability of human infection could be systematically analyzed. However, under natural convection conditions, the BPs diffusion disturbed by human walking in tomb chambers would also pollute some 
important cultural relics. The study of murals contamination during visitors walking is extremely important, especially in modern society which emphasizes cultural inheritance.

In order to preferably inheriting and preserving the murals and other precious cultural heritage in the open tombs, we surveyed the Two Mausoleums of Southern Tang Dynasty in Nanjing, China which is a typical tomb open to visitors and preserved a large number of exquisite murals eroded by microorganisms. For revealing the diffusion mechanism, deposition position and potential contamination risk of BPs in the tomb during visitor walking, the Shun Ling under the most serious contamination in the tomb was used as a physical model in this study. In addition, long-term experiments including the continued monitoring of environmental parameters, repeatedly collection, culture, and plate count analysis of the BPs in the tomb have been performed. The computational fluid dynamics (CFD) including the dynamic mesh technology were both used to reveal the movement of $\mathrm{BPs}$ when visitors were walking. Moreover, the contamination degree of the murals in the chamber and the influence of visitor disturbance on the deposition of BPs on the murals were dynamically analyzed. This research can provide scientific evidence for controlling the deposition of BPs on the murals in typical open tombs. Furthermore, a reference for the sustainability of visitor visits to certain special sites and the protection of similar cultural treasures which were open to visitors were provided.

\section{Research Object}

Shun Ling is the tomb of Emperor Li Jing, one of the largest tombs of emperors in the Five Dynasties and Ten Kingdoms. It was built in the Northern Song Dynasty (960-1127 AD) which inherits the basic characteristics of tomb building since Sui and Tang Dynasty. Exquisite stone sculptures and paintings are preserved. They are of great value to the study of architecture, emperor tomb system, and art in Tang and Song Dynasty. Shun Ling was excavated by the Nanjing Museum from 1950 to 1951 and protected locally. The maintenance and reinforcement were carried out in 1956. The drainage channels were built under the tomb in 1962. Since 1981, the cemetery has been further repaired and reinforced. The moisture-proof measures have been taken. The protection scope has been delineated, and surrounding environment has been rectified. In 1988, it was listed as a national key cultural relic protection unit. However, in recent years, the murals in the tombs which have a high historical research value have been seriously damaged due to the influx of tourists. Moreover, in order to better promote the development of tourism industry, the Conservation and Management Institute of the Two Mausoleums of Southern Tang Dynasty had not implemented strict measures to limit the visits of tourists. To improve this situation, the physical model of the Shun Ling of the Two Mausoleums of Southern Tang Dynasty was established according to field measurement and The Excavation Report of The Two Mausoleums of Southern Tang Dynasty. As shown in the Figure 1a, the main structure is divided into lobby, the main chamber: front chamber $(\mathrm{Fc})$, middle chamber $(\mathrm{Mc})$, rear chamber (Rc), 8 small chambers (Zone 1-8) and the corridor of Fc, Mc, Rc (Fcc, Mcc, Rcc). The position of the human body model was taken as the coordinate origin of $\mathrm{X}, \mathrm{Y}$, and $\mathrm{Z}$ axis to establish the model. The measured length of Shun Ling is $25.2 \mathrm{~m}$, and the maximum width (between Zone 7 and Zone 8 ) is $10.7 \mathrm{~m}$. The inlet is $2.55 \mathrm{~m}$ in length, $3.4 \mathrm{~m}$ in width and $3.0 \mathrm{~m}$ in height, and $1.0 \mathrm{~m}$ high from the indoor ground. The other specific dimensions are shown in Table 1. 
(a)

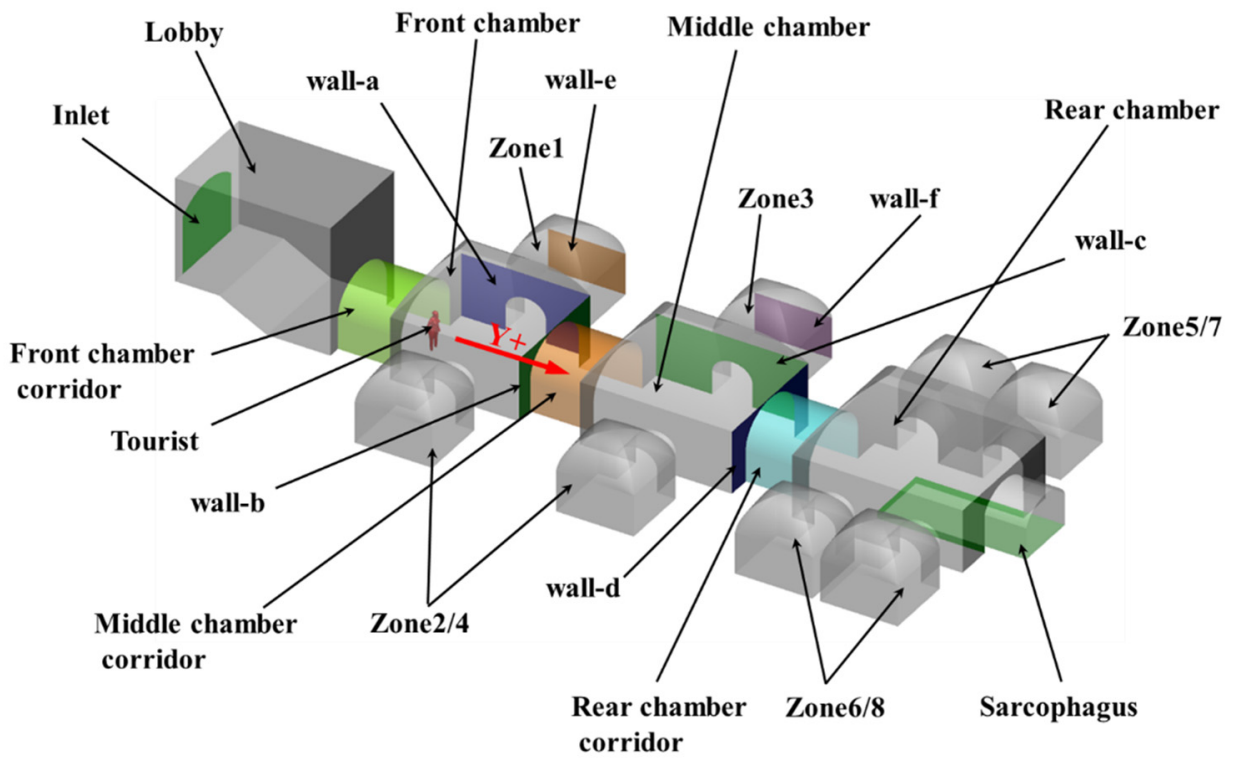

(b)

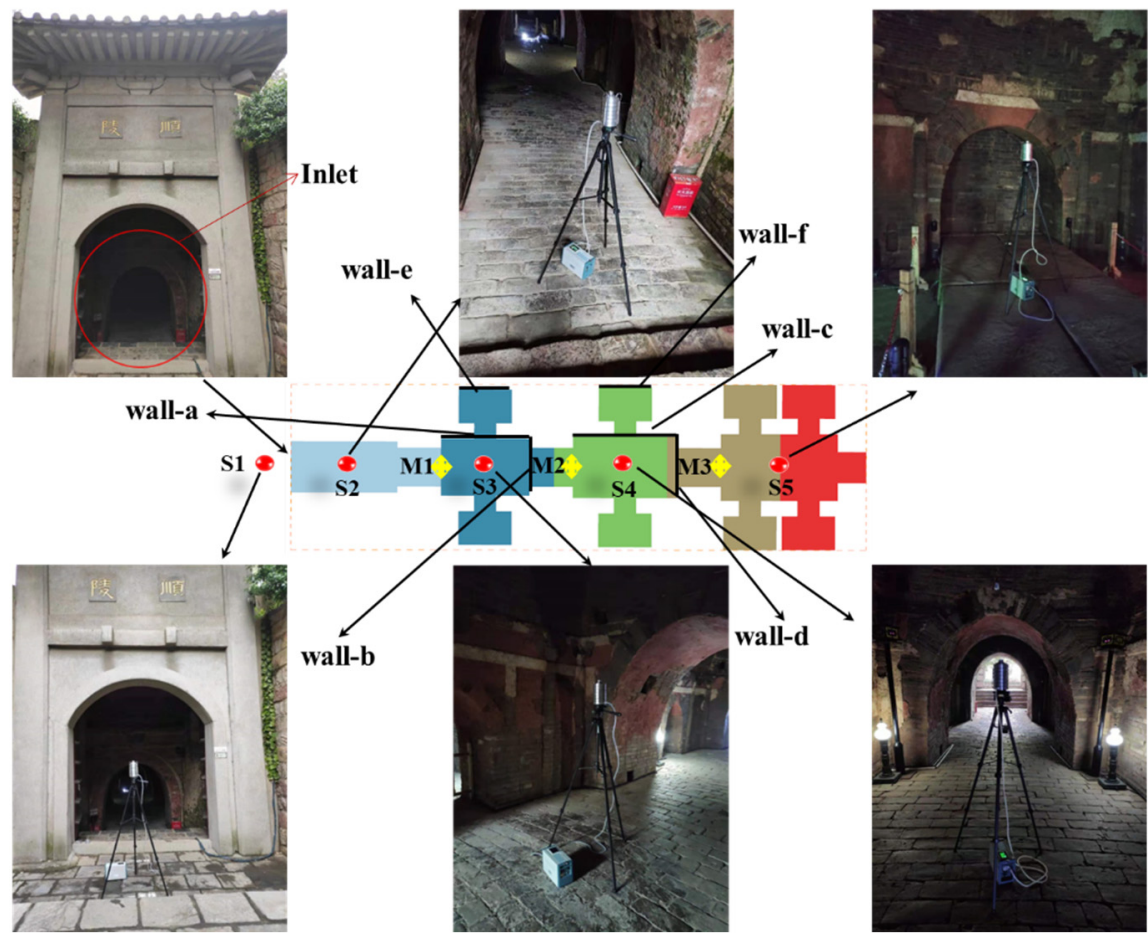

Figure 1. (a) Physical model of the Shun Ling; (b) arrangement of concentration sampling points and wind speed and temperature monitoring points.

Table 1. The main specific size information of the Shun Ling in the Two Mausoleums of Southern Tang Dynasty.

\begin{tabular}{lcccccc}
\hline & $\begin{array}{c}\text { Front } \\
\text { Chamber } \\
(\mathbf{F c})\end{array}$ & $\begin{array}{c}\text { Middle } \\
\text { Chamber } \\
\mathbf{( M c )}\end{array}$ & $\begin{array}{c}\text { Rear } \\
\text { Chamber } \\
\mathbf{( R c )}\end{array}$ & $\begin{array}{c}\text { The } \\
\text { Corridor of } \\
\text { Fc, Mc, Rc }\end{array}$ & $\begin{array}{c}\text { Zone 1-8 } \\
(\mathbf{Z 1 - Z 8 )}\end{array}$ & $\begin{array}{c}\text { The } \\
\text { Corridor of } \\
\mathbf{Z 1 - Z 8}\end{array}$ \\
\hline Length $(\mathrm{m})$ & 4.07 & 4.80 & 5.38 & 2.55 & 2.45 & 1.30 \\
Width $(\mathrm{m})$ & 3.73 & 4.00 & 4.35 & 2.60 & 2.20 & 1.00 \\
Heigh $(\mathrm{m})$ & 4.81 & 4.92 & 5.36 & 2.55 & 3.16 & 1.60 \\
\hline
\end{tabular}


As shown in Figure 1b, five sampling points (S1-S5) were set during experimental process: one meter away from the entrance to the tomb chamber, in the center of the lobby, and in the center of the Fc, Mc, and Rc, respectively. As shown in Figure 1a, all of these points were set by considering the symmetry of the chamber structure and the line for human body walking. The six-stage Anderson sampler were used to collect fungi in the air. The sampling flow were all set to $28.3 \mathrm{~L} / \mathrm{min}$, and the sampling time were all set to $5.0 \mathrm{~min}$. After the collection, the Petri dishes in the sampler were taken out and numbered, and then placed in a constant temperature incubator at $37^{\circ} \mathrm{C}$ for $48 \mathrm{~h}$ before counting.

The ANSYS Fluent 2020R2 was used for simulation. The visitor model was located at the origin of coordinates and starts to walk in a straight line along the positive direction of $Y$ axis $(Y+$ direction $)$ during time $=200-210 \mathrm{~s}$ with a speed of $5.0 \mathrm{~m} / \mathrm{s}$. In reality, the calorific value of the head and neck is different from that of the body when people wear clothes without a hat. Consequently, the calorific value of the head and neck was set as $150 \mathrm{~W} / \mathrm{m}^{2}$, and other parts of the body was set as $50 \mathrm{~W} / \mathrm{m}^{2}$ [31,32]. The velocity of $0.5 \mathrm{~m} / \mathrm{s}$ was chosen to meet basic needs of visitor's sightseeing. Compared with the BPs from the environment, the number of BPs released by visitors due to respiration metabolism was very small. Therefore, visitor was not considered as the main source of BPs release in this study, and it was assumed that all BPs in the chamber came from the outside air.

According to the size of the six-stage Andersen sampler aperture at all magnitude, three typical particles of $1.6 \mu \mathrm{m}, 2.7 \mu \mathrm{m}$, and $4.0 \mu \mathrm{m}$ which were the median diameters in the device were selected for the unsteady discrete phase simulation.

\section{Methodology}

\subsection{Airflow Simulation}

Indoor airflow is generally turbulent, which could be simulated by LES (Large Eddy Simulation), RANS (Reynolds Averaged Navier-Stokes), and DNS (Direct Numerical Simulation) turbulence models. However, the higher computer memory and longer calculation time were both required to apply the LES model for indoor flow field simulation [33], so it is not the first choice of this study. Gao discussed the simulation accuracy of standard $k-\varepsilon$ model and RNG $k-\varepsilon$ model for unsteady flow field, and the robustness of the simulated standard $k-\varepsilon$ model was superior to the low- $k-\varepsilon$ model [34]. In addition, Realizable $k-\varepsilon$ model was widely used in air flow simulation and was often used in the simulation of complex indoor air flow field [35]. When the flow characteristics changed into natural convection, the appropriate turbulence model should be switched according to the characteristics of the required sampling points, which could improve the simulation accuracy and save computational resources. Therefore, the turbulence model of Realizable $k-\varepsilon$ was adopted, and an enhanced-wall function was used in this study. The realizable $k-\varepsilon$ equation was as follows:

$$
\frac{\partial(\rho \varphi)}{\partial t}+\nabla \cdot(\rho \varphi \vec{V})=\nabla \cdot\left(\Gamma_{\varphi} \nabla \varphi\right)+S_{\varphi}
$$

where $\rho$ and $\vec{V}$ are the density and velocity vector of air, $\varphi$ represents any velocity components in the direction of the coordinate axis, $\Gamma_{\varphi}$ represents the effective diffusion coefficient of $\varphi$, and $S_{\varphi}$ is the source term.

In this paper, ANSYS Fluent 2020R2 was used to solve the differential equations, and the above differential equation was discretized into algebraic equations on unstructured tetrahedral meshes by finite volume method. The least squares element method for gradient discretization was applied and PRESTO scheme was used to discretize the pressure. In addition, the momentum, energy, $k$ and $\varepsilon$ equations were discretized by second order headwind. For the convergent solution, the scaling velocity and continuity residuals reach $10^{-4}$, and the energy residuals reach $10^{-6}$.

The inlet was set as a pressure inlet, the turbulivity of air supply was set at $5 \%$, and the temperature was set at $30^{\circ} \mathrm{C}$. All solid surfaces in the chamber were provided with no-slip conditions, and the wall treatment was enhanced to solve the turbulence characteristics 
near the wall. The Boussinesq approximation was adopted for the fluid. Finally, the operating density was set at $1.165 \mathrm{~kg} / \mathrm{m}^{3}$ for continuous phase simulation.

\subsection{Bioaerosol Particles Simulation}

The Lagrangian particle tracking method with a discrete random walk model was used to represent the diffusion of the suspended fungal community in the burial chamber. The differential equation to solve the motion of the particles is as follows:

$$
\frac{d \overrightarrow{u_{p}}}{d t}=F_{D}\left(\vec{u}-\vec{u}_{p}\right)+\frac{\vec{g}\left(\rho_{p}-\rho\right)}{\rho_{p}}+\vec{F}
$$

where $\vec{u}$ and $\overrightarrow{u_{p}}$ represent the velocity of airflow and BPs; $\rho$ and $\rho_{p}$ represent the density of airflow and BPs; $\vec{g}$ represents gravitational acceleration; $\vec{F}$ represents the additional forces acting on the BPs.

According to the size of the six-stage Andersen sampler aperture at all magnitude, the fungal community in the chamber was simulated as three kinds of spherical BPs with different diameters of $1.6 \mu \mathrm{m}, 2.7 \mu \mathrm{m}$, and $4.0 \mu \mathrm{m}$. In this study, before these particles were injected for the transient state calculation, the steady state calculation of the airflow field in the chamber was calculated. The time step was set as $1.0 \mathrm{~s}$, the number of iterative steps was set as 20 steps per second, and calculating for $900 \mathrm{~s}$. After calculation, the data of relevant sampling points could be accurately extracted for comparison and verification, and the diffusion law of BPs could be comprehensively tracked. Considering the released microbial particle size and the ratio of microbial particle density to gas density are large, the pressure gradient force and virtual mass force could be ignored. According to the study of Zhao et al., the Saffman lift force and thermophoretic force were considered in this study [36].

The outdoor fungal community coupled with the natural convection field was evenly injected into the interior of the chamber from the inlet. The higher number of the parcels representing similar properties to BPs which were tracked by ANSYS Fluent, the better the convergence could be achieved and the closer to the real situation. Therefore, more than 720,000 parcels were used in this study to simulate the distribution of indoor fungi, which was sufficient to produce a convergence statistic that balanced computational cost and accuracy. The mass flow rate of BPs was defined as:

$$
q=\rho V A
$$

where the $q$ is the mass flow rate of BPs; $\rho$ is the microbial particle density; $V$ is the inlet of wind speed; $A$ is the inlet area.

In the process of BPs diffusion, some of the BPs escape through the backflow above the inlet. Therefore, the boundary condition of escape was adopted for the whole inlet. When the BPs impact within the walls and the rooves of the chamber which were the rigid surface, not enough energy were hosted to reflect. In fact, the boundary conditions of all walls were set to "trap" and the residuals of all parameters in the calculation process could reach a small order of magnitude. In this study, three kinds of BPs would facilitate the comparison and verification of concentration simulation and experiment in each chamber. A higher anastomosis was presented between the concentration change trend of each main chamber and the experimental results along $\mathrm{Y}+$ direction in Figure 1.

\subsection{Dynamic Mesh Simulation}

The dynamic mesh model was widely used to predict the impact of human motion on the flow field around the body and the distribution of BPs, and the effect was significant $[21,28,37]$. Therefore, a dynamic mesh model was used to simulate the visitor walking inside the chamber. In the calculation process, the calculation domain was divided into dynamic and static areas, and the mesh was updated only in the dynamic area, which 
avoids the possibility of negative volume caused by the deformation of the entire large space mesh in the calculation process. It can also improve the quality of the deformed mesh, save calculation time, and improve the accuracy of the results. The mesh processing has been widely used in the dynamic simulation of interior moving subjects and convincing results were obtained $[32,38]$. A spring-based method of smoothing and remeshing was used to update the mesh. The UDF (user-defined-functions) was used to compile the walking operation instructions. The visitor walked from the Fc to the corridor of Mc (Mcc) at a speed of $0.5 \mathrm{~m} / \mathrm{s}$ within $200 \mathrm{~s}$ to $210 \mathrm{~s}$. Due to the changes of the mesh during visitor walking, the time step was gradually reduced from time $=200 \mathrm{~s}$, and the mesh update was previewed. Finally, the time step of the unsteady state simulation was adjusted from $1 \mathrm{~s}$ to $0.02 \mathrm{~s}$, a total of $500 \mathrm{steps}$, so as to realize the whole movement process of the visitor. The form of integral conservation relation dependent on the boundary motion of visitor was as follows:

$$
\frac{d}{d t} \int_{V} \rho \phi d V+\int_{\partial V} \rho \phi\left(\vec{u}-\vec{u}_{g}\right) \cdot d \vec{A}=\int_{\partial V} \Gamma \nabla \phi \cdot d \vec{A}+\int_{V} S_{\phi} d V
$$

where $\rho$ is the air density, $\vec{u}$ is the air velocity vector, $\vec{u}_{g}$ is the velocity of the mesh moving, $\Gamma$ is the diffusion coefficient, $S_{\varphi}$ represents the source term, and $\partial V$ represents the boundary of the control volume.

\subsection{Experimental Method}

In order to verify the distribution of BPs under the condition of numerical simulation of unsteady natural convection, a field experiment was conducted in Shun Ling of the Two Mausoleums of Southern Tang Dynasty. The experimental process is shown in Figure 1b. The six-stage Anderson sampler was placed at the sampling points (S1-S5), and the experimental height was $1.6 \mathrm{~m}$. In addition, the average value of wind speed and temperature should be taken at three monitoring points $1.8 \mathrm{~m}$ from the ground at the central axis of the entrance of each main chamber. Therefore, anemometer (TSI 8465) and temperature meter were also used to measure for several times [39].

Some studies have pointed out that many culturable strains have better colony stability, which may be the main reason for the destruction of murals [1]. Besides, several research showed that fungi are the main microbial types threatening the preservation of ancient murals [40]. Moreover, due to the geographical location of Two Mausoleums of Southern Tang Dynasty, the environment is humid and causes the exchange of hot and humid air inside and outside. This also provides a good living environment for some fungal-derived plants such as moss, cyanobacteria, lichens, etc., [41]. According to the research reports on mildew in the colored paintings of Two Mausoleums of Southern Tang Dynasty, the fungi genus causing mildew in the colored paintings of Shun ling burial chamber were mainly Rhizopus, Aspergillus, Penicillium, and other fungal species. Therefore, culturable fungal samples were collected for biological culture and the culture medium for fungi was potato glucose AGAR medium added with chloramphenicol to inhibit the growth of bacteria, as shown in the Figure 2.

Each sampling point (S1-S5) was collected twice, and let to stand for $15 \mathrm{~min}$ before each sampling. The time interval between the two collections was also $15 \mathrm{~min}$, so as to ensure that the air flow velocity in the environment of the chamber was stable before the second collection. The culture process and results are shown in Figure $2 b, c$. The plate counting method was used to count the fungal colonies after culture. Then, according to the formula (5), the number of bacterial colonies was converted into the concentration of culturable fungi in the chamber.

$$
C\left(\mathrm{CFU} / \mathrm{m}^{3}\right)=\frac{1000 \times N(\mathrm{CFU})}{T(\mathrm{~min}) \times F(\mathrm{~L} / \mathrm{min})}
$$


where $C$ represents the concentration of culturable fungi in the chamber environment, $N$ represents the number of colonies after culture, $F$ represents the flow rate, and $T$ is the sampling time during sampling.

(a)

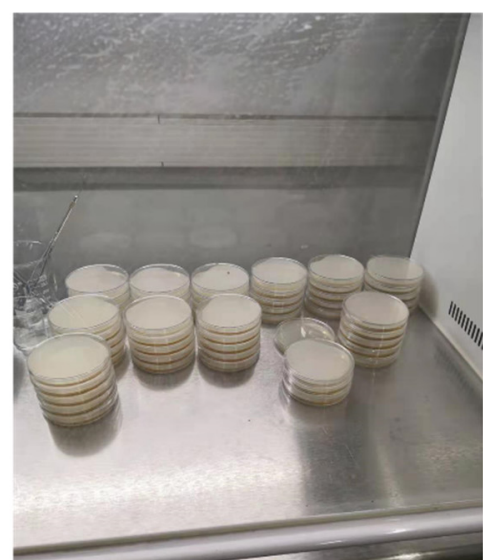

(b)

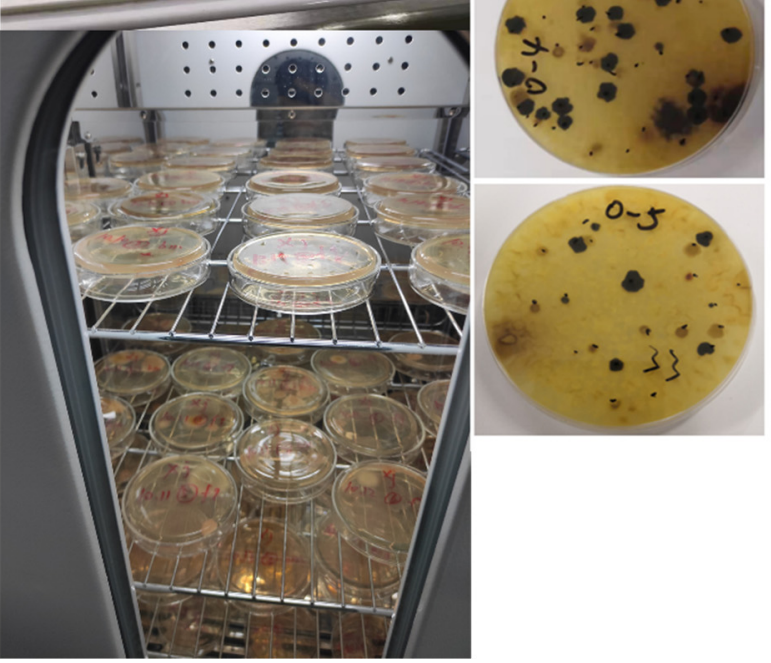

(c)

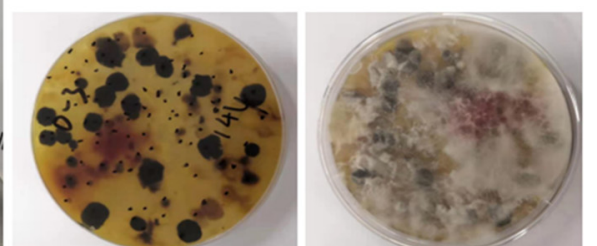

.
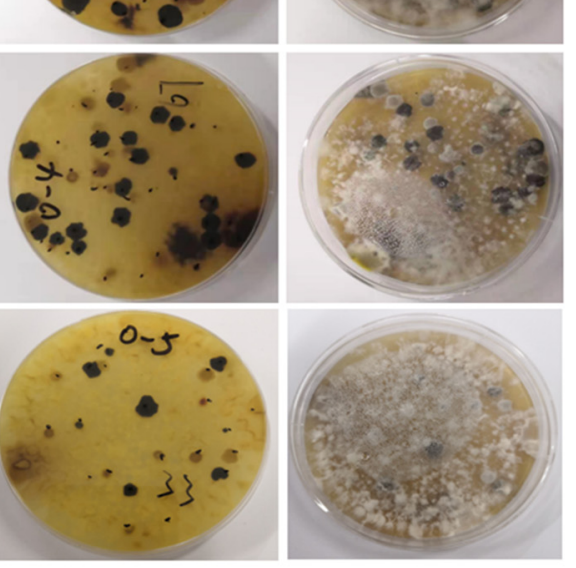

Figure 2. (a) Medium preparation process; (b) fungal incubation process; (c) incubation results.

\section{Results and Discussion}

\subsection{Verification of Airflow and Particle Numerical Simulation}

For validating the numerical model of this study, the physical model of Shun Ling was established which was based on reference to The Excavation Report of The Two Mausoleums of Southern Tang Dynasty and the real size measured in the field. Then the simulation corresponding to the experiment was carried out. Three sets of parallel wind speed and temperature were measured at the inlet height of each main chamber at $1.8 \mathrm{~m}$, and the average value was compared with the simulation result. The grids of 2314189, 4432237, and 7232603 were tested and verified, respectively, as shown in Figure 3. The results showed that there was no significant difference in the air flow field and temperature field between the three grids. Therefore, 2314189 grids were used to save calculation time in the subsequent study. The inlet adopted the boundary condition of pressure, the temperature outside the chamber was set to $30^{\circ} \mathrm{C}$, and the wall temperature in the chamber room was set to $10^{\circ} \mathrm{C}$. The gas flowed depending on the air density difference caused by the temperature difference between inside and outside. 


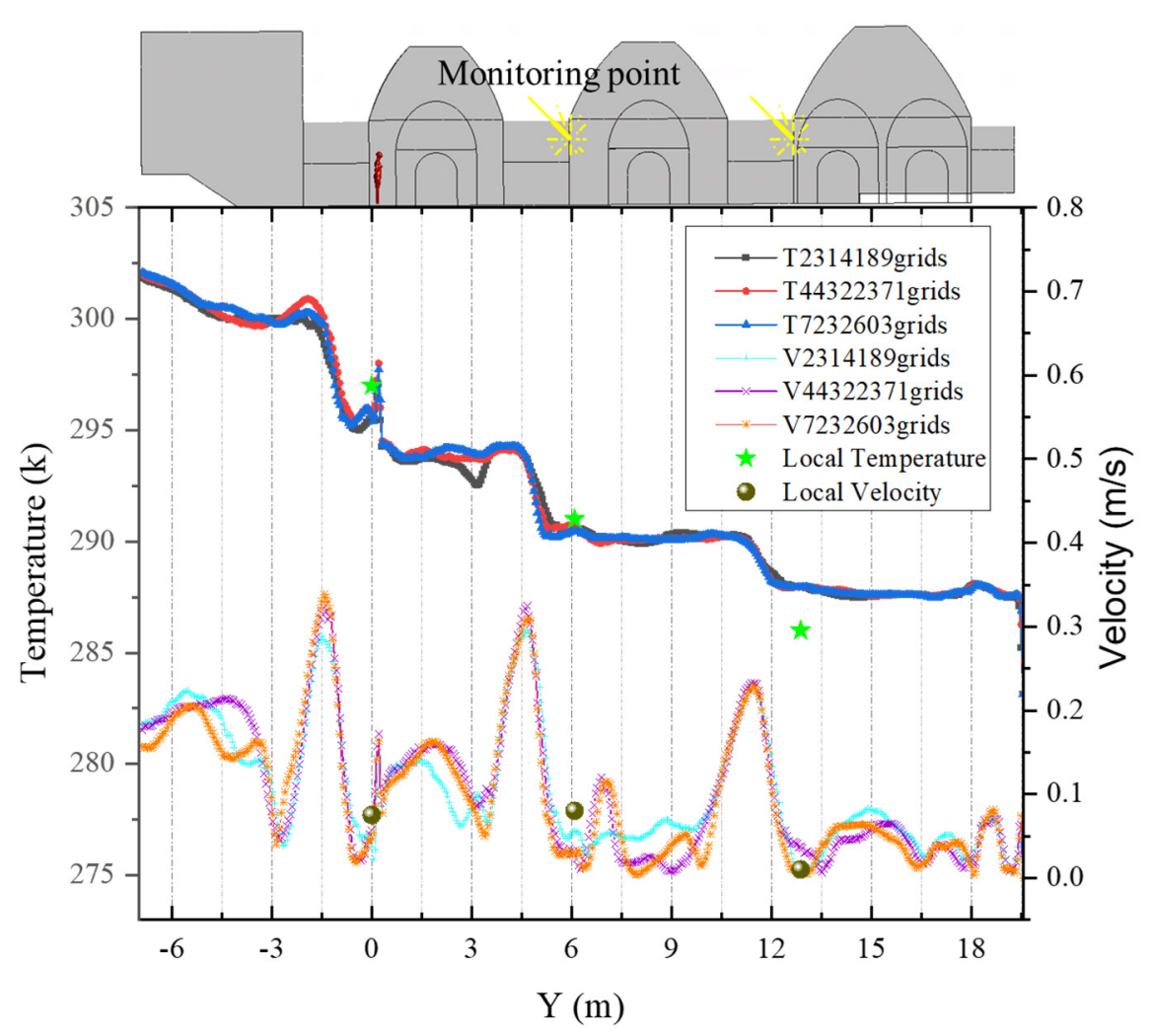

Figure 3. Comparison of simulated wind speed and temperature on the axis $\mathrm{Z}=1.8 \mathrm{~m}$ with experimental values and mesh independence verification.

For the simulation of discrete phase, the bioaerosol particles with the median size of $1.6 \mu \mathrm{m}, 2.7 \mu \mathrm{m}$, and $4 \mu \mathrm{m}$ in the Anderson sampler were converted to the corresponding mass flow rate of $7.35116 \times 10^{-13} \mathrm{~kg} / \mathrm{s}, 7.16707 \times 10^{-12} \mathrm{~kg} / \mathrm{s}$, and $5.00632 \times 10^{-11} \mathrm{~kg} / \mathrm{s}$ with the measured outdoor concentration. These BPs were injected into the interior of the chamber from the normal direction of the inlet surface, and the method of releasing BPs during the process was consistent with the actual situation of the chamber. When the visitor remains standing, the dynamic concentration of BPs at the vertical height $1.2 \mathrm{~m}$, $2.4 \mathrm{~m}$, and $3.6 \mathrm{~m}$ from the visitor's foot was recorded every $100 \mathrm{~s}$. In addition, during time $=200-300 \mathrm{~s}$, the concentration of BPs is recorded every $10 \mathrm{~s}$ to observe the changes in the spatial concentration caused by visitor walking in the interior of the chamber in a short time. The sampling points of wall was helpful to observe the changes in the attachment of BPs on the wall, and further explore the migration, diffusion, and deposition rules of BPs in the chamber. As shown in Figure 4, the concentration inside the chamber reached a relative balance at time $=900 \mathrm{~s}$. The BPs of three sizes were compared with the average experimental sampling concentration in the Fc, Mc, and Rc. The results show that the concentration trends and magnitudes of simulated and experimental values are consistent. Therefore, subsequent simulations are considered reliable after verification. 


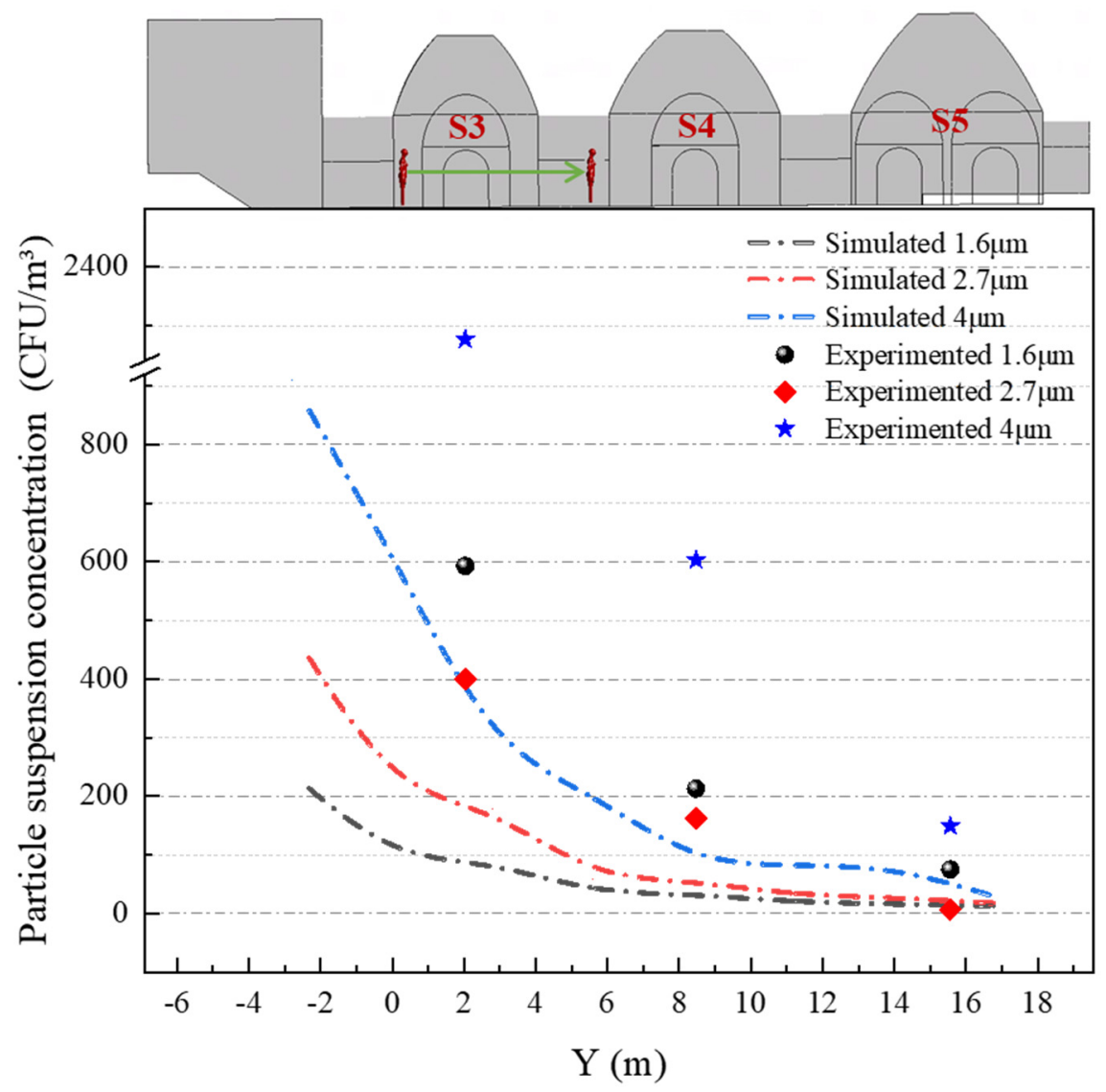

Figure 4. Verification of concentration of BPs of three diameters.

\subsection{The Influence of Visitor Walking on the Air Distribution}

Visitor walking would destroy the original air distribution characteristics of the interior of the chamber and affect the diffusion of BPs. As shown in Figure 5, there were iso-surface diagrams of the vorticity and velocity streamlines of different cross-sections from Fc to Mc. Among them, Figure $5 \mathrm{a}, \mathrm{b}$ show the situation of visitor standing up, and Figure $5 \mathrm{c}, \mathrm{d}$ show the situation of visitor walking.

It can be seen from the velocity field distribution in the Figure $5 a, b$ that the upper air velocity was faster under the condition of natural ventilation while visitor remained standing. This is due to that the outside airflow had a higher temperature and lower density than the internal airflow, and the air mainly flows on the top after entering the tomb. However, the air flow was so weak in the Z1-Z8 which were small space and only connected to the lower area of the main chambers. Accounting for the combined effect of heat pressure and human body thermal plume, the air flow in the corridor suddenly entered the tall main chamber. The air flow would continue to flow into the main chamber for a certain distance as a result of inertia. The parabolic rise airflow was divided into two at the top of each main chamber, and convolved into two larger vortices in the forward and backward directions, and flows on the top wall.

Besides, during the walking of visitor, the form of airflow around the human body changes, producing obvious wakes and thermal plumes. Considering the sightseeing of visitors, the walking speed was set to a low $0.5 \mathrm{~m} / \mathrm{s}$. Consequently, the wake would reclaim dominance in the micro-environment airflow near the visitors during walking. Under the combined action of the thermal effect, a pair of reverse vortices were formed in the back area of the visitor, which extend to downward, backward, and on both sides. In addition, the airflow disturbance caused by the visitor walking was obvious, and the airflow speed can even be greater than that of the visitors walking. Therefore, the spatial migration of BPs in the moving direction and the vertical direction was enhanced. 

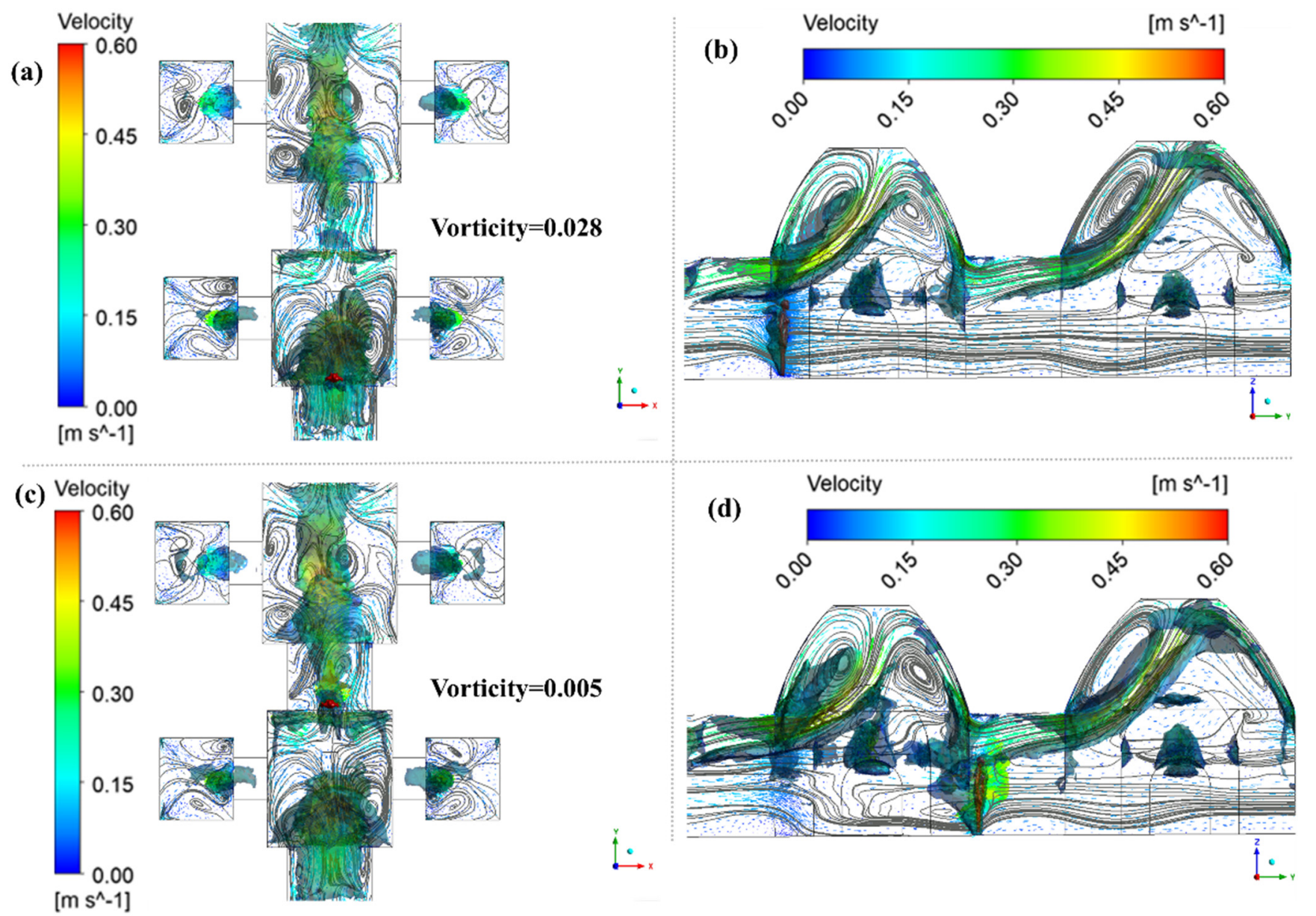

Figure 5. Vorticity iso-surface diagram and velocity streamline diagram of different cross-sections: (a) the $\mathrm{Z}=1.2 \mathrm{~m}$ section of visitor standing up; (b) the $X=0 \mathrm{~m}$ section of visitor standing up; (c) the $Z=1.2 \mathrm{~m}$ section of visitor walking; (d) the $\mathrm{X}=0 \mathrm{~m}$ section of visitor walking.

It can also be seen from Figure $5 b$,d that a denser vortex was produced while visitor was walking, and the vortex was mainly concentrated on the sides and above the head of the visitor. In the process of dynamic walking, the relatively stable "laminar flow" mode was short-lived. Owing to the small volume and mass of BPs, they were easily affected by vortices in the turbulent flow field. Thus, BPs gather at the edge of the vortex and follow the vortex to produce obvious migration.

The disturbance caused by visitor walking was the main reason for the changes of the airflow around the visitor and near the wall. After the visitor walking, some BPs were convolved in the newly generated vortices at different positions near the rooves and wall of each chamber, and could not be separated. This changed the concentration of the microenvironment in different areas of the chamber space, and further deepened the contamination of the murals in the corresponding locations. It can be seen from Figure 5 that more vortices moving to the small chambers on both sides are generated after visitor walking. It strengthened the diffusion and migration of BPs into the small chambers. Compared with each main chamber, as the high initial concentration, the influence of disturbance after visitor walking is not obvious. On the contrary, the concentration of BPs in the small chamber will change more obviously, and the contamination degree of the wall mural becomes more serious.

\subsection{The Influence of Visitor Walking on the BPs Concentration in the Main Chambers}

The concentration curve of BPs at different heights in the compartments is shown in Figure 6. The picture on the left shows the concentration change curve of each main 
chamber ( $\mathrm{Fc}, \mathrm{Mc}$, and $\mathrm{Rc}$ ) before and after the walking of the visitor at three kinds of heights $(Z=1.2 \mathrm{~m}, Z=2.4 \mathrm{~m}$ and $Z=3.6 \mathrm{~m})$ during time $=0-900 \mathrm{~s}$. The picture on the right corresponds to local concentration changes during time $=200-300 \mathrm{~s}$ of each main chamber On the central axis is the local concentration change during time $=200-300 \mathrm{~s}$ in the corridor of the middle chamber (Mcc).

The walking of visitor was during time $=200-210 \mathrm{~s}$, at a speed of $0.5 \mathrm{~m} / \mathrm{s}$ from the $\mathrm{Fc}_{\mathrm{C}}$ to the Mcc. It can be seen from Figure 5 that the walking of visitor produces eddy currents. This disturbance makes the BPs enter the corridor of the middle chamber from the front chamber earlier, and gather at the top of the corridor for a long time. The rising trend of BPs concentration in the Fc and Mc has slowed down significantly. However, due to the short and limited disturbance of visitors' activities, after time $=900 \mathrm{~s}$, the concentration of BPs in each chamber reached a stable level again, and was similar to the concentration of visitor remaining standing. It can be seen that the walking of the visitor would have a significant impact on the distribution of BPs within a certain range of the chamber.

Obviously, the higher the height in the same area, the higher the concentration. This is because the BPs are affected by the thermal pressure updraft and the Saffman lift force, and a large number of particles adhere to the upper space and flow, forming an obvious vertical stratification phenomenon. The temperature change in the Mc and Rc is not obvious, the air flow velocity is reduced, and the BPs move slower accordingly. Consequently, the concentration of BPs gradually decreases from the inlet to the inside of the chamber. The air flow velocity in the upper half of the chamber space was relatively high, the number of BPs was larger, and the moving was faster. The change of concentration at $Z=1.2 \mathrm{~m}$ was significantly slower than that at $Z=2.4 \mathrm{~m}$ and $Z=3.6 \mathrm{~m}$, and the closer it was to the back chamber, the more obvious it was in the whole chamber model.

During time $=200-300 \mathrm{~s}$, the change of the concentration in the front chamber was more dramatic after the visitor stopped compared to visitor standing, especially in the upper area. In addition, the increase of concentration in the Fc obviously slowed down, and the time for the concentration of each chamber to reach stable is also delayed accordingly. The reason was that visitor walk from the Fc to the Mcc at a lower speed, which will produce smaller turbulent airflow and longer influence time, resulting in an increase in the residence time of BPs in the same area. At the same time, upward airflow in the moving wake is mostly seen. The BPs were continuously transported to the upper area of the Fc, resulting in more obvious changes in the concentration of BPs in the upper area relative to the lower area.

The concentration of BPs in the Mcc was during time $=210-300 \mathrm{~s}$, which fluctuates greatly compared to visitor remaining standing, and the concentration increases significantly after visitor stopping walking. This was because for a given distance, a slower walking speed would lead to a longer induced wake development, resulting in a large number of vortices that convolve BPs near the visitor body, and carry them to the Mcc while interacting. After time $=210 \mathrm{~s}$, the wake shrank after the visitor stopped. The disturbed airflow continues to move forward due to inertia. The remaining airflow continues to transport the BPs forward and upward under the influence of the thermal plume effect. This allowed part of the suspended BPs that should have accumulated in the Fc to be transported to the Mcc, and also explained the variation of the BPs concentration in the Fc and Mc over time.

Due to the influence of convoluted air flow caused by the walking of visitor, many BPs suspended in the Mcc for a long time, resulting in a significantly lower concentration of BPs in the Rc than when the visitor remains standing. With the weakening of the influence of vortex and the diffusion of natural convection, the concentration of BPs in the Rc reached a concentration similar to that of visitor remaining standing at time $=900 \mathrm{~s}$.

The above analysis shows that the concentration of BPs has changed greatly within $250 \mathrm{~s}$ after the visitor stopped, and the range of influence was from the Fc to the Rc. Moreover, more BPs move into the small room due to the generation of eddy currents on both sides of the visitor, causing greater potential harm to the mural in the small chamber. 


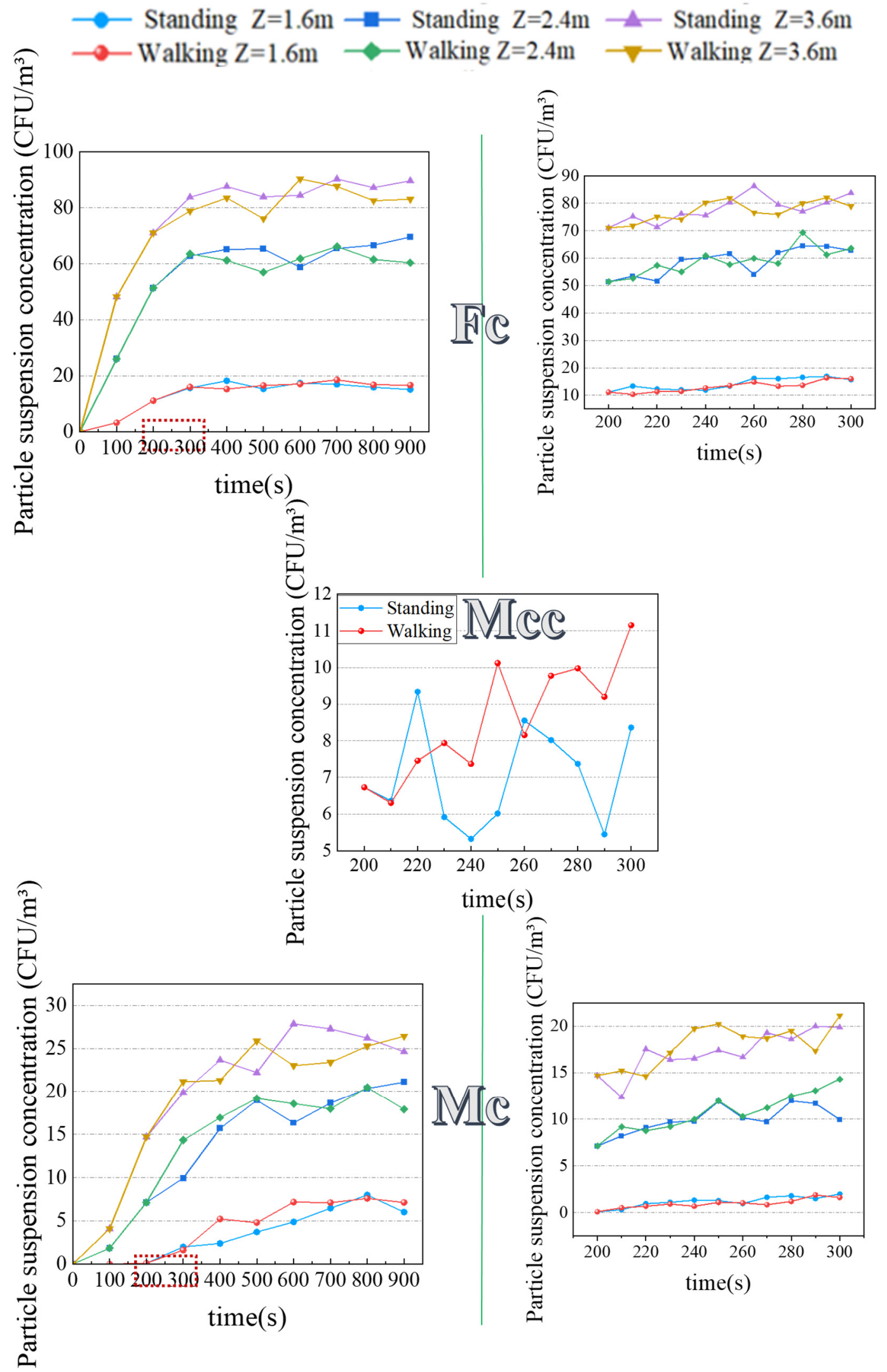

Figure 6. Cont. 


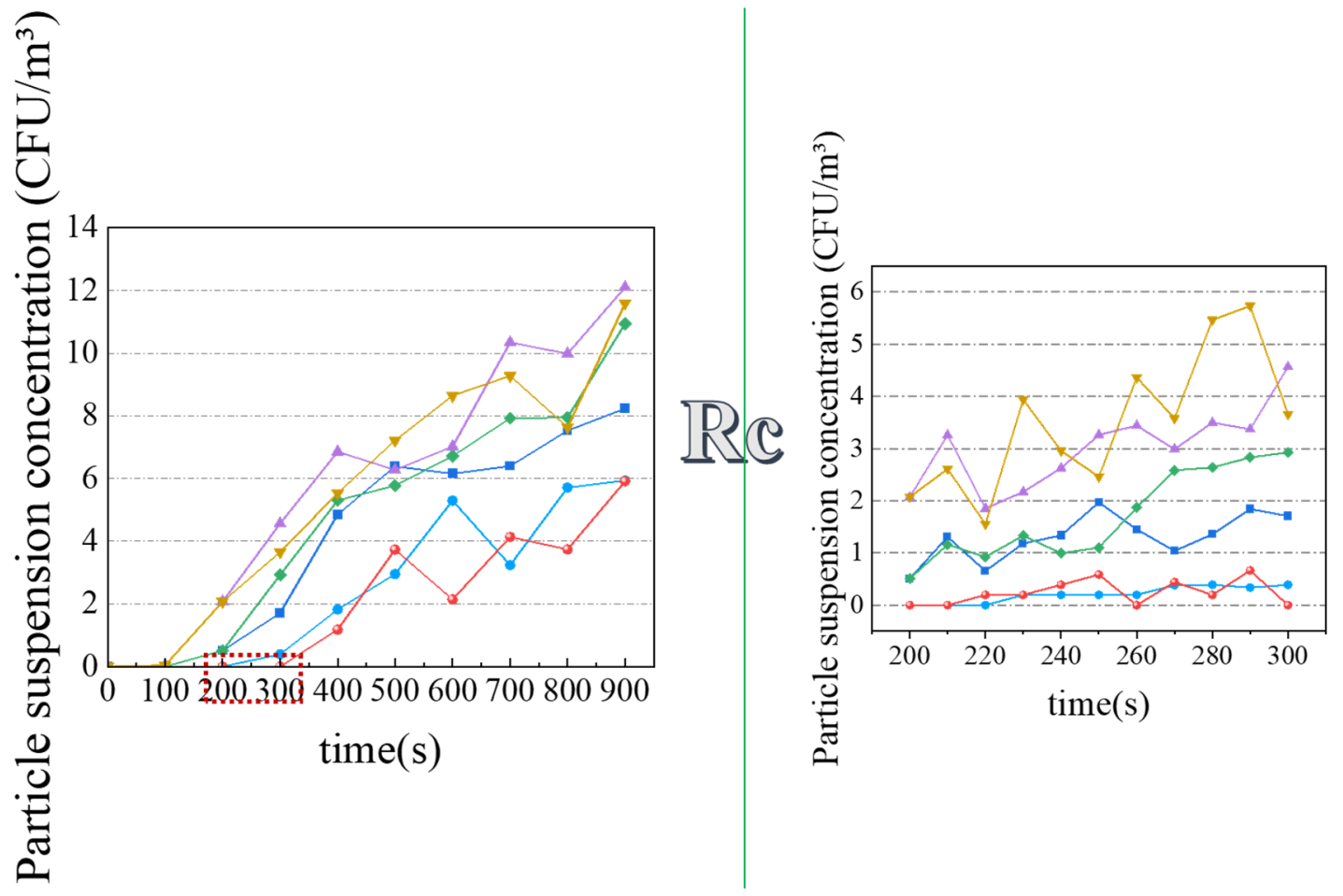

Figure 6. Concentration changes of the BPs in main champers at different heights.

\subsection{The Influence of Visitor Walking on the Distribution Characteristics of the BPs on the Murals}

As shown in Figure 7a, it was a histogram of the number and proportion of particles on the walls and rooves in different regions at $900 \mathrm{~s}$. There is obviously no significant change in the total number of BPs whether walking or not. However, after the walking of the visitor, the change of deposition position was mainly concentrated in the Fc, the $\mathrm{Mc}$, and the small chambers on both sides within the movement range of the people. In addition, the proportion of BPs attached to the wall of each main chamber increased to varying degrees in each main chamber.

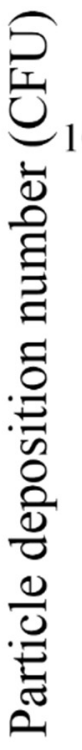

(a)

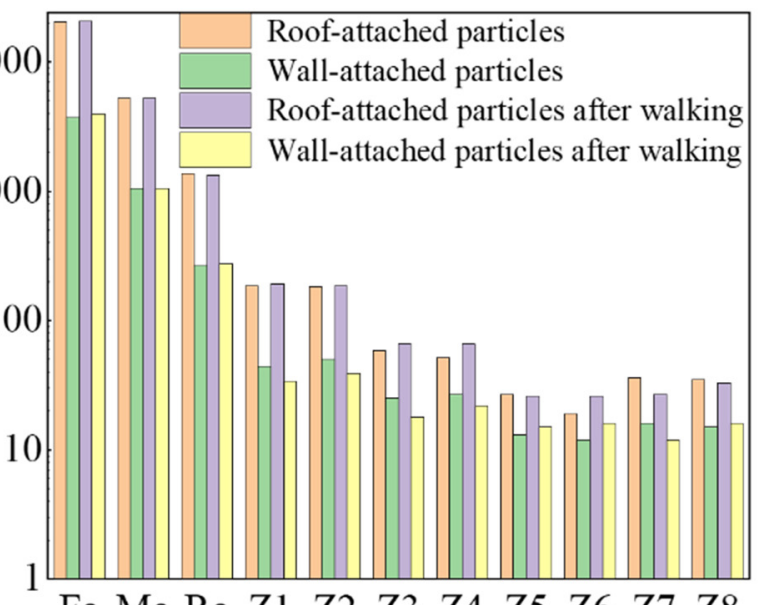

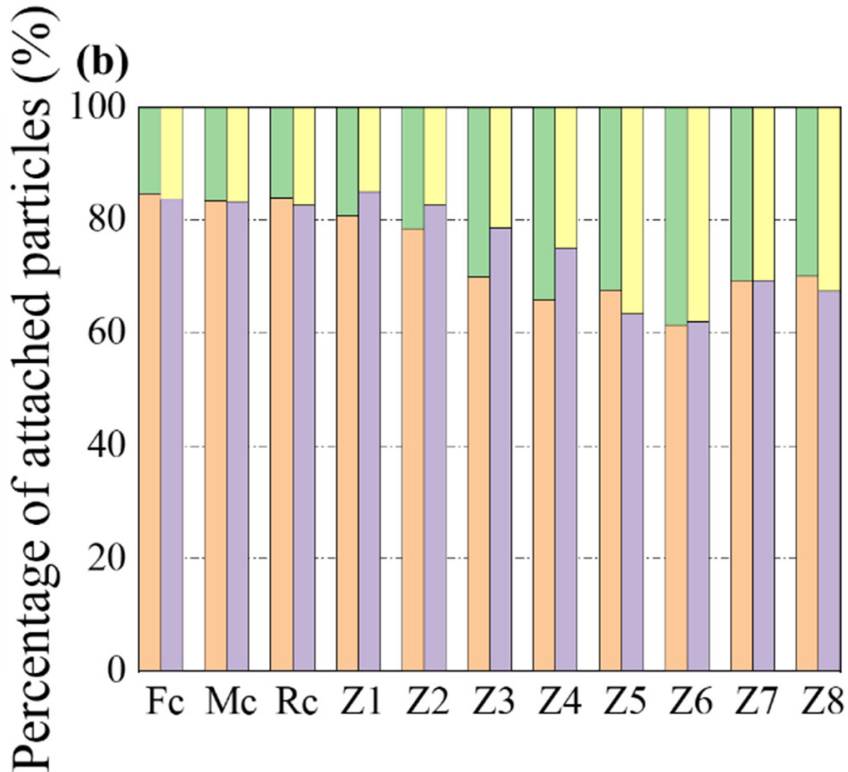

(b)

Figure 7. Distribution of deposition BPs in different chambers at time $=900 \mathrm{~s}$ both visitor walking and standing up: (a) the number of BPs on the walls and rooves; (b) the proportion of BPs on the walls and rooves. 
Since visitor only walk from the front room to the middle room corridor, the airflow range was limited. Owing to the low speed, the influence of small turbulence was extremely weak compared with the introduction and diffusion of Bioaerosol particles by natural convection over a long period of time. So, in the calculation time of $900 \mathrm{~s}$, the number of BPs attached to the walls and rooves of each chamber was basically similar to that when the visitor remained standing. However, near the moving range of visitor, the concentration of $\mathrm{BPs}$ and the attachment position of BPs on the walls and rooves have varying degrees of change over a period of time.

In the Figure $7 \mathrm{~b}$, it can be clearly seen that the proportion of BPs attached to the walls has increased in different degrees in each main chamber after visitor walking. The main reason is that the walking of visitor disrupts the balance of airflow distribution in the chamber. As a result, some of the BPs that should have been attached to the rooves stayed in the lower part, thereby increasing the possibility of trap on the wall.

The BPs deposition location distribution of typical wall surfaces is showed in Figure 8. On the left is the case that visitor remains standing, and the right is after walking. It can be clearly seen that BPs were mostly attached to a vertical height of more than $0.6 \mathrm{~m}$. Because of the heat pressure under the condition of natural convection, there is a significant updraft. The distribution of wind speed below the height in the chamber was complicated but completely weak. BPs were extremely affected by the updraft and Saffman lift, so there was a significant stratification phenomenon.

The distribution of the BPs deposition location of wall-a and wall-b in the Fc with or without visitor walking is shown on Figure $8 \mathrm{a}, \mathrm{b}$. The number of BPs deposited in the wall-a increased significantly after visitor walked from the Fc to the Mcc, and increased by about $50 \%$ during time $=200-400 \mathrm{~s}$. This was due to that the wake generated by visitor walking and the thermal updraft caused by the heat dissipation of visitor had a greater impact on the velocity field. Consequently, the front chamber produces varying degrees of turbulence, the time for BPs depositing on the wall was delayed, and the deposition location of BPs was changed. At the same time, it can be seen that the deposition position of BPs on the wall-a was obviously biased toward the visitor's advancement ( $\mathrm{Y}+$ direction). It was revealed that the walking of the visitor drives part of the suspended BPs in the walking area to move forward, which makes the location of BPs deposition spatially change.

However, the deposition position of BPs was obviously shifted downward on the wall-b compared with wall-a. This was because human body turbulence mainly affects the middle layer where the airflow speed was low and the temperature changes were not obvious. The BPs that should continue to spread near the rooves and the BPs that should diffuse with the airflow in the middle area were convolved in the vortex generated by the walking of the visitor and were difficult to escape. Thus, the concentration of BPs in the middle layer became higher, and BPs were accordingly trapped at a lower position on the wall.

The BPs deposition location of wall-c and wall-d in the Mc with or without visitor walking is shown in Figure $8 \mathrm{c}, \mathrm{d}$. Compared with visitor remaining standing, the number of BPs deposited increased significantly after visitor walking. Especially during time $=400-600 \mathrm{~s}$, the deposition growth rate exceeds $100 \%$.

Compared with wall-d, wall-c has more attached number after time $=400 \mathrm{~s}$, and the deposition time of most BPs was delayed. It was due to that the attachment process of the airflow parallel to the moving direction of people is slower, and there are more vortices near the wall, which make it more difficult for BPs to be captured. Nevertheless, the attachment process of airflow perpendicular to the direction of visitor walking was faster, and there were fewer vortices near the wall, so the BPs were easier to capture. This conclusion can also be verified in Figure 5. 
(a)
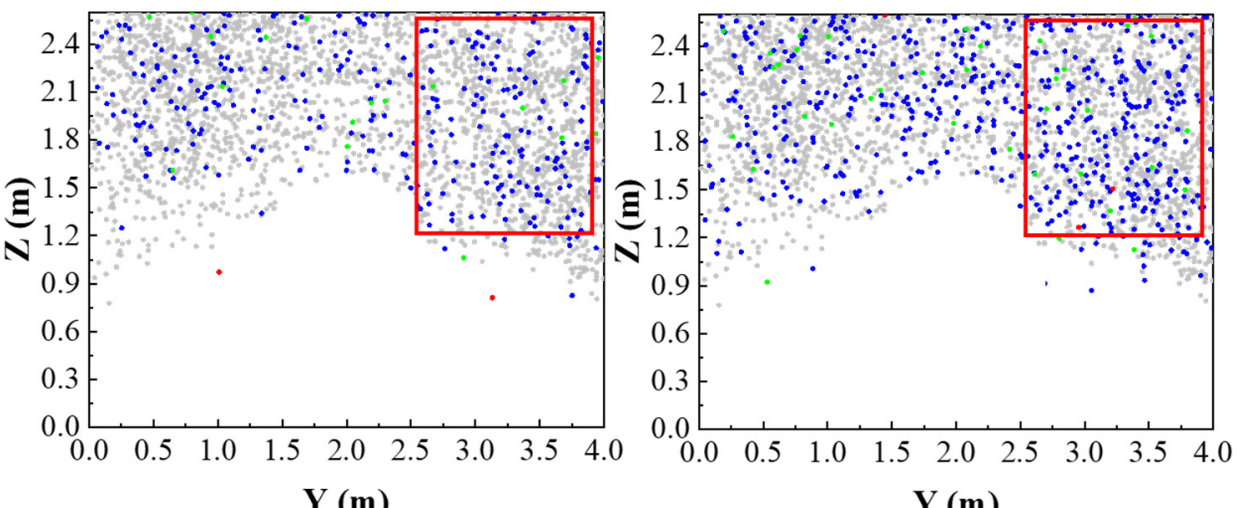

(b)
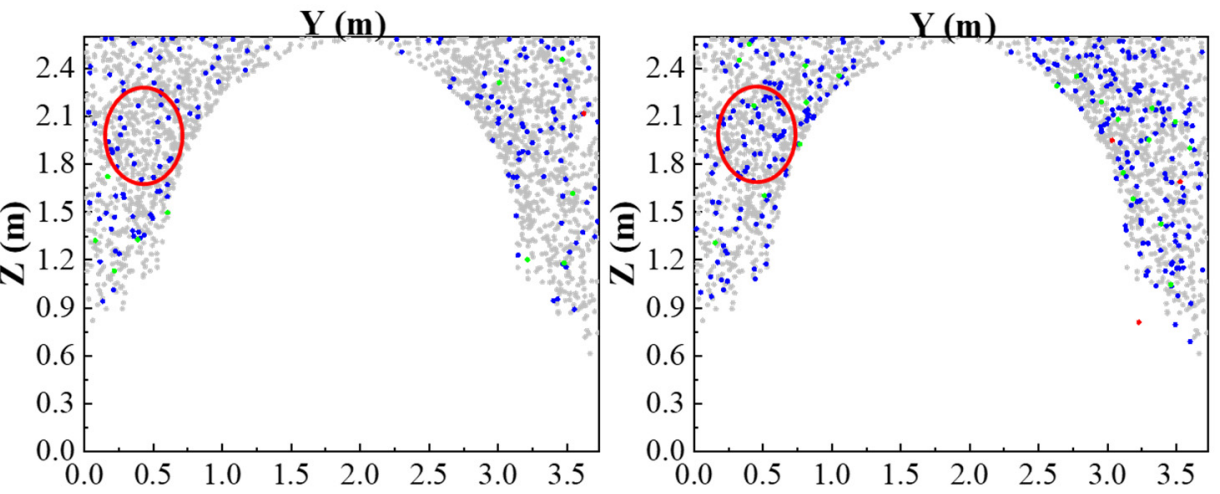

(c)
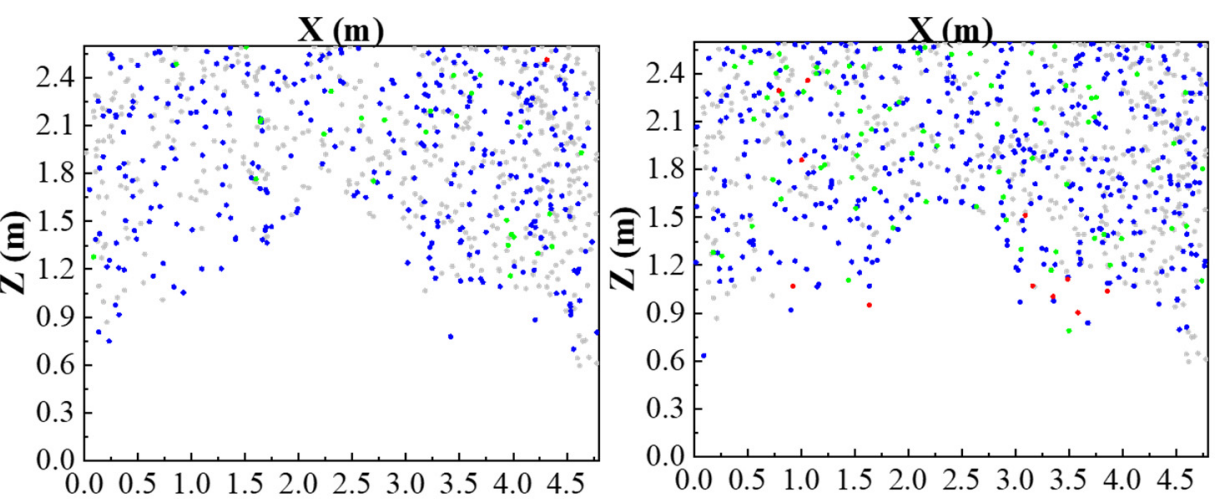

(d)
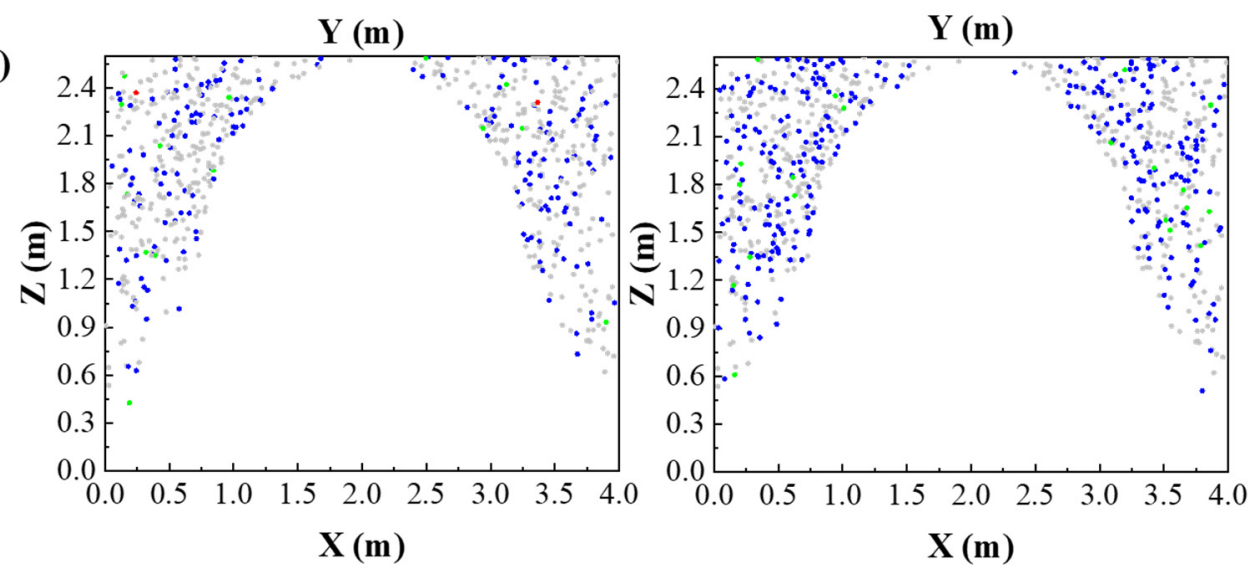

Figure 8. Cont. 
(e)
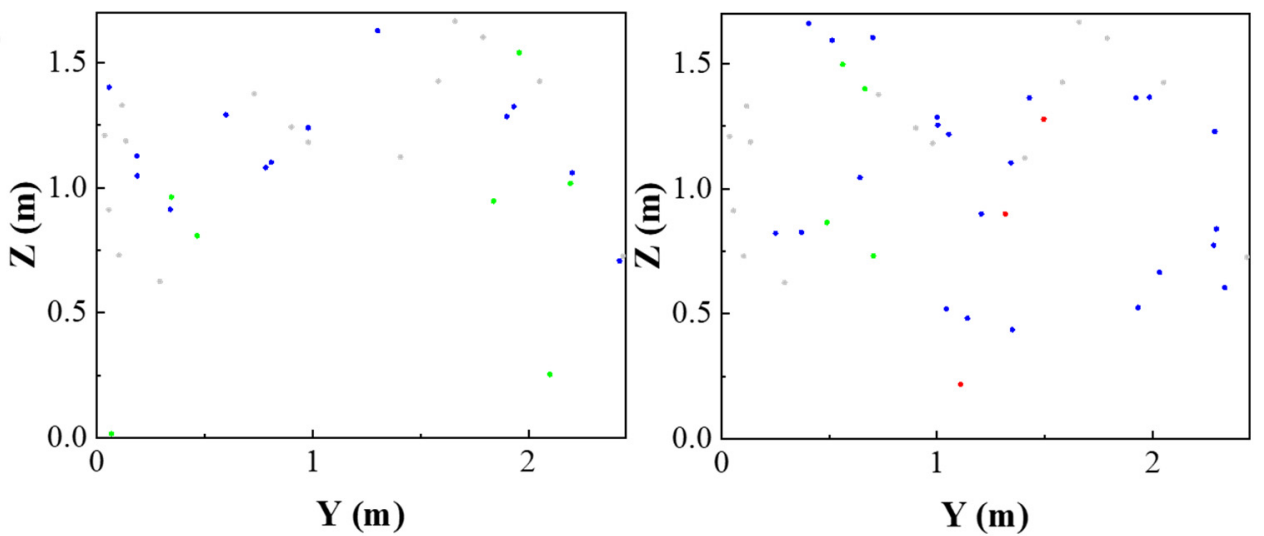

(f)
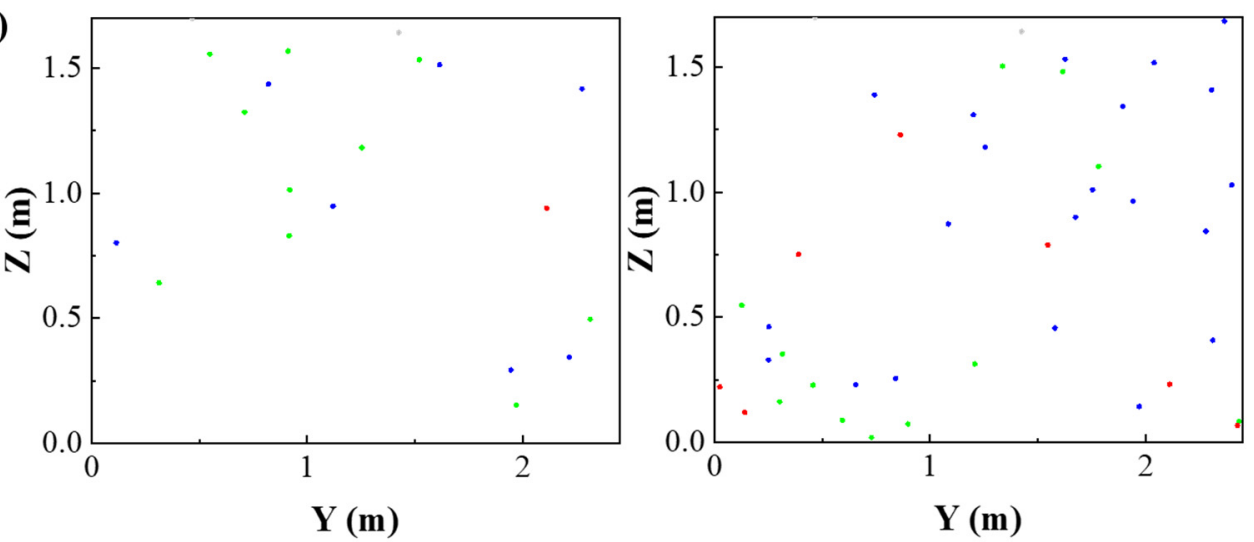

Figure 8. Distribution of BPs deposition locations on typical wall surfaces before and after visitor walking: (a) distribution of BPs deposition locations on wall-a; (b) distribution of BPs deposition locations on wall-b; (c) distribution of BPs deposition locations on wall-c; (d) distribution of BPs deposition locations on wall-d; (e) distribution of BPs deposition locations on wall-e; (f) distribution of BPs deposition locations on wall-f.

The BPs deposition location of the inner wall (wall-e and wall-f) of the Z1 and the Z3 with or without visitor walking was shown on Figure 8e,f. Under the condition of visitor walking, the number of BPs attached to the wall more than doubles, and the time of BPs attachment was delayed during time $=200-400 \mathrm{~s}$. More specifically, after the visitor walking, the airflow pattern became very complicated within a certain period of time, which is particularly obvious in the $\mathrm{Y}+$ direction, that is, in the main chamber area. However, after a period of time, this complexity was gradually transferred to the small room, causing a part of the BPs in the main room space to flow into the small room. In addition, the BPs originally retained in the cell space are also affected by the disturbance, and then hit the wall surface.

In this study, the visitor walking at the speed of $0.5 \mathrm{~m} / \mathrm{s}$ during time $=200-210 \mathrm{~s}$ will have varying degrees of impact on the number and location distribution of BPs deposited on the wall of each chamber in a short time. Compared with the main chamber, the changes in the small rooms were more obvious. However, during time $=210-900 \mathrm{~s}$, the natural convection allows BPs to continue to pass in and diffuse in the chamber. The impact of visitor's movements in a short period of time on the deposition of Bioaerosol particles in the mural is gradually reduced. Consequently, in the calculation and statistical time of $900 \mathrm{~s}$, the number of BPs attached to the walls and rooves of each room was basically similar to that when the visitor remained standing.

But at the same time, the real situation is more complex. For instance, when personnel activities are more intense and secular or the strength of natural convection is weakened, it account for the decrease of the temperature difference between indoor and outdoor, etc. All of these may cause the influence of personnel activities on the microbial deposition on 
the surface of the mural to occupy a dominant position, and ultimately cause irreversible microbial hazards. Therefore, more in-depth analysis and research are required based on different factors such as the openness of the chamber, the number of visitors, the speed and way of sightseeing, the actual indoor airflow form, the coupling of indoor heat and humidity sources, etc.

What can be determined at present is that human disturbance will have a certain impact on the bioaerosol contamination of the murals in a limited space and time range. Therefore, for the purposes of better inheriting and preserving precious cultural heritage, highly efficient mural protection schemes should be obtained and implemented to the problem, such as establishing an external air buffer room at the inlet to reduce the number of BPs; setting up a mechanical ventilation device to find appropriate ventilation form that can effectively remove BPs in the tomb; setting up more glass barriers close to the wall to reduce the potential hazards caused by visitor visits to the murals; placing more guardrails around the precious cultural relics to limit the range of visits and to reduce the large-scale air flow disturbance during visitor visits; reasonable control of the number of visitors and the visit time of visitors; reducing the input and diffusion of BPs caused by personnel disturbance; reproducing precious murals for tourists to see, which are more polluted while walking; adding air filtration equipment to the upper part of the tomb to reduce the accumulation of BPs in the upper part of the tomb under natural convection, thus protecting murals and other valuable cultural relics, etc.

In summary, the diffusion of BPs in the tomb, deposition and potential contamination risk on the murals were studied in detail using experimental and simulation methods. The results provide a scientific basis for the protection of murals when the tourists visit similar open tombs, and also provide theoretical support for appropriately opening closed tombs to the visitors. Future studies should be focused on the impact of the number of visitors and complicated visiting behavior on the contamination risk of murals. Moreover, highly efficient mural protection schemes should be implemented. The removal rate of BPs and the improvement degree of mural contamination should also be verified and compared.

\section{Conclusions}

In this study, visitor walking was analyzed from both experimental and CFD simulations by establishing a typical open chamber scene. The spatial concentration distribution of typical diameters of the BPs in the chamber and the contamination position changing law of the murals were analyzed. The mechanism of human activities on the micro-environment of the air flow field in the chamber was discussed. At the same time, the microbial contamination of the murals that may be caused by continuous personnel disturbance for a long time was considered, which provides a reference for the prevention and control of microbial diseases of the chamber murals and the protection of murals. The main conclusions of the study are as follows:

1. The visitor walking will disturb the original interior of the chamber and the airflow distribution characteristics. The process of walking produces denser eddy currents, combined with the comprehensive effect of the thermal plume. In addition, the eddy currents mainly move to the above of the visitor' head and the small chambers on both sides, which affect the movement and migration of the BPs.

2. Visitor walking causes the concentration of BPs to change greatly within $250 \mathrm{~s}$ after visitor stopped. The vortex generated by the disturbance of the visitor walking causes the BPs to enter the corridor of the middle chamber from the front chamber earlier, and gather at the roof of the corridor for a long time. Moreover, due to the generation of eddy currents on both sides of the visitor, more BPs move into the small chamber, which greatly increases the possibility of the contamination of the murals.

3. The deposition of BPs in the chamber is in line with the characteristics of airflow diffusion in the space. The rooves' BPs deposition number is significantly higher than the bottom wall deposition in the same area. After the visitor walking, the deposition 
number and ratio of the bottom wall were both increased, and the time required for deposition of BPs was prolonged.

4. During time $=200-400 \mathrm{~s}$, the deposition position on the murals of the main chamber parallel to the direction of human movement shifted to the walking direction. The deposition quantity could increase by $50 \%$. While the deposition position on the wall perpendicular to the direction of human movement shifted downward, and the deposition growth rate could exceed $100 \%$. The deposition quantity on the wall of small chamber increased by multiples. After the shifting, the contamination of degree at the corresponding position increased, but the original position decreased.

Author Contributions: Contributions made by the authors were as follows: conceptualization: Z.L.; methodology: Z.L., M.W., and H.C.; validation: Z.L., M.W., and H.C.; data analysis: Z.L., M.W., Y.W., and R.R.; writing: Z.L. and M.W.; review and editing: M.W., H.C., Y.W., R.R., and H.Z.; supervision: Z.L., M.W. and R.R.; project administration: Z.L. All authors have read and agreed to the published version of the manuscript.

Funding: This research was funded by the National Science and Technology Ministry of China (2019YFC1520700), the National Natural Science Foundation of China (No. 41977368), and Fundamental Research Funds for the Central Universities (No. 2020YJ007).

Institutional Review Board Statement: Not applicable.

Informed Consent Statement: Not applicable.

Data Availability Statement: Not applicable.

Conflicts of Interest: The authors declare no conflict of interest.

\section{References}

1. Ma, Y.; Zhang, H.; Du, Y.; Tian, T.; Xiang, T.; Liu, X.; Wu, F.; An, L.; Wang, W.; Gu, J.-D.; et al. The community distribution of bacteria and fungi on ancient wall paintings of the Mogao Grottoes. Sci. Rep. 2015, 5, 7752. [CrossRef] [PubMed]

2. Li, Y.; Li, X.; Jiang, Q.; Zhou, Q. Historical Study and Conservation Strategies of "Tianzihao" Colony (Nanjing, China)— Architectural Heritage of the French Catholic Missions in the Late 19th Century. Buildings 2021, 11, 176. [CrossRef]

3. Du, C.; Li, B.; Yu, W. Indoor mould exposure: Characteristics, influences and corresponding associations with built environmentA review. J. Build. Eng. 2021, 35, 101983. [CrossRef]

4. Sterflinger, K.; Pinar, G. Microbial deterioration of cultural heritage and works of art-Tilting at windmills? Appl. Microbiol. Biotechnol. 2013, 97, 9637-9646. [CrossRef]

5. Zorpas, A.A.; Skouroupatis, A. Indoor air quality evaluation of two museums in a subtropical climate conditions. Sustain. Cities Soc. 2016, 20, 52-60. [CrossRef]

6. Pangallo, D.; Kraková, L.; Chovanová, K.; Šimonovičová, A.; De Leo, F.; Urzì, C. Analysis and comparison of the microflora isolated from fresco surface and from surrounding air environment through molecular and biodegradative assays. World J. Microbiol. Biotechnol. 2012, 28, 2015-2027. [CrossRef]

7. Imperi, F.; Caneva, G.; Cancellieri, L.; Ricci, M.A.; Sodo, A.; Visca, P. The bacterial aetiology of rosy discoloration of ancient wall paintings. Environ. Microbiol. 2007, 9, 2894-2902. [CrossRef] [PubMed]

8. Warscheid, T.; Braams, J. Biodeterioration of stone: A review. Int. Biodeterior. Biodegrad. 2000, 46, 343-368. [CrossRef]

9. Liu, Z.; Yin, H.; Ma, S.; Wei, B.; Jensen, B.; Cao, G. Effect of environmental parameters on culturability and viability of dust accumulated fungi in different HVAC segments. Sustain. Cities Soc. 2019, 48, 101538. [CrossRef]

10. Abbasi, F.; Samaei, M.R.; Manoochehri, Z.; Jalili, M.; Yazdani, E. The effect of incubation temperature and growth media on index microbial fungi of indoor air in a hospital building in Shiraz, Iran. J. Build. Eng. 2020, 31, 101294. [CrossRef]

11. Ortega-Morales, O.; Montero-Muñoz, J.L.; Neto, J.A.B.; Beech, I.B.; Sunner, J.; Gaylarde, C. Deterioration and microbial colonization of cultural heritage stone buildings in polluted and unpolluted tropical and subtropical climates: A meta-analysis. Int. Biodeterior. Biodegrad. 2019, 143, 104734. [CrossRef]

12. Vasanthakumar, A.; DeAraujo, A.; Mazurek, J.; Schilling, M.; Mitchell, R. Microbiological survey for analysis of the brown spots on the walls of the tomb of King Tutankhamun. Int. Biodeterior. Biodegrad. 2013, 79, 56-63. [CrossRef]

13. Kiyuna, T.; An, K.D.; Kigawa, R.; Sano, C.; Miura, S.; Sugiyama, J. Molecular assessment of fungi in "black spots" that deface murals in the Takamatsuzuka and Kitora Tumuli in Japan: Acremonium sect. Gliomastix including Acremonium tumulicola sp. nov. and Acremonium felinum comb. nov. Mycoscience 2011, 52, 1-17. [CrossRef]

14. Lv, Y.; Zhou, Y.; Chen, X.; Zhao, T.; Liu, T.; He, X.; Liu, J.; Ye, X. Study on indoor and outdoor permeability coefficients and bacterial components, sources of fine particles in severe cold region of China. Sustain. Cities Soc. 2020, 55, 102020. [CrossRef] 
15. Wu, D.; Zhang, Y.; Li, A.; Kong, Q.; Li, Y.; Geng, S.; Dong, X.; Liu, Y.; Chen, P. Indoor airborne fungal levels in selected comprehensive compartments of the urban utility tunnel in Nanjing, Southeast China. Sustain. Cities Soc. 2019, $51,101723$. [CrossRef]

16. Ma, W.; Wu, F.; Tian, T.; He, D.; Zhang, Q.; Gu, J.-D.; Duan, Y.; Ma, D.; Wang, W.; Feng, H. Fungal diversity and its contribution to the biodeterioration of mural paintings in two 1700-year-old tombs of China. Int. Biodeterior. Biodegrad. 2020, 152, 104972. [CrossRef]

17. Wang, W.; Ma, X.; Ma, Y.; Mao, L.; Wu, F.; Ma, X.; An, L.; Feng, H. Seasonal dynamics of airborne fungi in different caves of the Mogao Grottoes, Dunhuang, China. Int. Biodeterior. Biodegrad. 2010, 64, 461-466. [CrossRef]

18. Bastian, F.; Jurado, V.; Novakova, A.; Alabouvette, C.; Saiz-Jimenez, C. The microbiology of Lascaux Cave. Microbiology 2010, 156, 644-652. [CrossRef]

19. Corzo, M.A.; Afshar, M. Art and Eternity: The Nefertari Wall Paintings Conservation Project, 1986-1992; Getty Conservation Institute: Santa Monica, CA, USA; Egyptian Antiquities Organization: Cairo, Egypt, 1993; pp. 3-18.

20. Demas, M.; Agnew, N. Valley of the Queens Assessment Report: A Collaborative Project of the Getty Conservation Institute and the Supreme Council of Antiquities, Egypt. Vol. 1, Conservation and Management Planning; Getty Conservation Institute: Los Angeles, CA, USA, 2012; pp. 163-227.

21. Chang, L.; Tu, S.; Ye, W.; Zhang, X. Dynamic simulation of contaminant inleakage produced by human walking into control room. Int. J. Heat Mass Transf. 2017, 113, 1179-1188. [CrossRef]

22. Ljungqvist, B.; Flynn, M.R. A review of wake effects on worker exposure. Ann. Occup. Hyg. 1995, 39, $211-221$.

23. Brohus, H.; Balling, K.D.; Jeppesen, D. Influence of movements on contaminant transport in an operating room. Indoor Air 2006, 16, 356-372. [CrossRef]

24. Saidi, M.; Sajadi, B.; Molaeimanesh, G. The effect of source motion on contaminant distribution in the cleanrooms. Energy Build. 2011, 43, 966-970. [CrossRef]

25. Ge, Q.; Li, X.; Inthavong, K.; Tu, J. Numerical study of the effects of human body heat on particle transport and inhalation in indoor environment. Build. Environ. 2013, 59, 1-9. [CrossRef]

26. Tao, Y.; Inthavong, K.; Tu, J. A numerical investigation of wind environment around a walking human body. J. Wind. Eng. Ind. Aerodyn. 2017, 168, 9-19. [CrossRef]

27. Pei, G.; Taylor, M.; Rim, D. Human exposure to respiratory aerosols in a ventilated room: Effects of ventilation condition, emission mode, and social distancing. Sustain. Cities Soc. 2021, 73, 103090. [CrossRef]

28. Tao, Y.; Inthavong, K.; Tu, J. Computational fluid dynamics study of human-induced wake and particle dispersion in indoor environment. Indoor Built Environ. 2016, 26, 185-198. [CrossRef]

29. Wang, J.; Chow, T.-T. Numerical investigation of influence of human walking on dispersion and deposition of expiratory droplets in airborne infection isolation room. Build. Environ. 2011, 46, 1993-2002. [CrossRef]

30. $\mathrm{Wu}, \mathrm{Y}$; Gao, N. The dynamics of the body motion induced wake flow and its effects on the contaminant dispersion. Build. Environ. 2014, 82, 63-74. [CrossRef]

31. Holmér, I.; Nilsson, H. Heated manikins as a tool for evaluating clothing. Ann. Occup. Hyg. 1995, 39, 809-818. [CrossRef]

32. Sadrizadeh, S.; Tammelin, A.; Ekolind, P.; Holmberg, S. Influence of staff number and internal constellation on surgical site infection in an operating room. Particuology 2014, 13, 42-51. [CrossRef]

33. Choi, J.-I.; Edwards, J.R.; Choi, J.-I.; Edwards, J.R. Large-eddy simulation of human-induced contaminant transport in room compartments. Indoor Air 2011, 22, 77-87. [CrossRef] [PubMed]

34. Gao, F.; Wang, H.; Wang, H. Comparison of different turbulence models in simulating unsteady flow. Procedia Eng. 2017, 205, 3970-3977. [CrossRef]

35. Romano, F.; Marocco, L.; Gustén, J.; Joppolo, C.M. Numerical and experimental analysis of airborne particles control in an operating theater. Build. Environ. 2015, 89, 369-379. [CrossRef]

36. Zhao, B.; Zhang, Y.; Li, X.; Yang, X.; Huang, D. Comparison of indoor aerosol particle concentration and deposition in different ventilated rooms by numerical method. Build. Environ. 2004, 39, 1-8. [CrossRef]

37. Liu, Z.; Liu, H.; Rong, R.; Cao, G. Effect of a circulating nurse walking on airflow and bacteria-carrying particles in the operating room: An experimental and numerical study. Build. Environ. 2020, 186, 107315. [CrossRef]

38. Poussou, S.B.; Mazumdar, S.; Plesniak, M.; Sojka, P.E.; Chen, Q. Flow and contaminant transport in an airliner cabin induced by a moving body: Model experiments and CFD predictions. Atmos. Environ. 2010, 44, 2830-2839. [CrossRef]

39. Liu, X.; Lv, X.; Peng, Z.; Shi, C. Experimental study of airflow and pollutant dispersion in cross-ventilated multi-room buildings: Effects of source location and ventilation path. Sustain. Cities Soc. 2020, 52, 101822. [CrossRef]

40. Marco, A.; Santos, S.; Caetano, J.; Pintado, M.; Vieira, E.; Moreira, P.R. Basil essential oil as an alternative to commercial biocides against fungi associated with black stains in mural painting. Build. Environ. 2020, 167, 106459. [CrossRef]

41. Cennamo, P.; Montuori, N.; Trojsi, G.; Fatigati, G.; Moretti, A. Biofilms in churches built in grottoes. Sci. Total. Environ. 2016, 543, 727-738. [CrossRef] 